\title{
Branch-first aortic arch replacement with no circulatory arrest or deep hypothermia
}

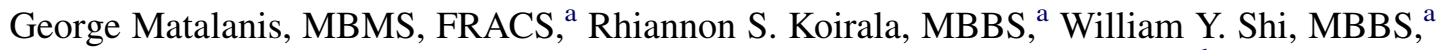 \\ Philip A. Hayward, BMBCh, FRCS, ${ }^{a}$ and Peter R. McCall, MBBS, FANZCA ${ }^{\text {b }}$
}

\begin{abstract}
Background: For aortic arch surgery, the potential risks of deep hypothermic circulatory arrest with or without antegrade cerebral perfusion have been widely documented. We hereby describe our early experience with a "branch-first continuous perfusion" technique that, by avoiding deep hypothermia and circulatory arrest, has the potential to reduce morbidity and mortality.
\end{abstract}

\begin{abstract}
Methods: Arterial perfusion is peripheral using femoral and axillary inflows. Disconnection of each arch branch, and anastomosis to the trifurcation graft, proceeds sequentially from the innominate to the left subclavian artery, with continuous perfusion of the heart and viscera by lower body and brain by upper body arterial return. After the descending aorta is clamped, the debranched arch may then be replaced and connected to the ascending aorta before the common stem of the trifurcation graft is joined to the arch graft. Thirty patients underwent this technique. Twelve patients were operated on for aortic dissection and the remainder for aneurysms.
\end{abstract}

Results: With experience, minimum pump temperature rose from $16^{\circ} \mathrm{C}$ to $34^{\circ} \mathrm{C}$. There was $1(3.3 \%)$ death, and $2(6.7 \%)$ patients had neurological dysfunction. Extubation was achieved within 24 hours in $12(40 \%)$ patients, whereas $14(47 \%)$ left the intensive care unit within 2 days. Ten $(33 \%)$ patients were discharged from the hospital within 7 days. Eight (27\%) patients required no transfusion of blood or blood products.

Conclusions: This technique brings us closer to the goal of arch surgery without cerebral or visceral circulatory arrest and the morbidity of deep hypothermia. Early results are encouraging. (J Thorac Cardiovasc Surg 2011;142:809-15)

Current techniques of cerebral protection during aortic arch surgery frequently incorporate antegrade cerebral perfusion, which has been shown to improve outcomes especially in the more prolonged and complex cases. ${ }^{1,2}$ Nonetheless, variable periods of circulatory arrest are frequently used for insertion and removal of antegrade perfusion cannulas or to facilitate arch branch reconstruction. ${ }^{2}$ Even short periods of cerebral circulatory arrest have been shown to be deleterious for higher mental function. ${ }^{3}$ Furthermore, circulatory arrest and arch branch manipulation and/or cannulation allow opportunity for cerebral embolization of air and debris. This may explain the persistent cerebral morbidity in some current series. Other techniques, using unilateral cerebral perfusion, often via the right axillary artery, while seeming to avert cerebral circulatory arrest, still have issues related to contralateral hemispheric hypoperfusion or ipsilateral hyperperfusion. ${ }^{2,4}$

\footnotetext{
From the Departments of Cardiac Surgery ${ }^{\mathrm{a}}$ and Anaesthesia, ${ }^{\mathrm{b}}$ Austin Hospital, University of Melbourne, Melbourne, Australia.

Disclosures: Authors have nothing to disclose with regard to commercial support.

Received for publication May 4, 2010; revisions received Dec 3, 2010; accepted for publication Jan 10, 2011; available ahead of print Feb 17, 2011.

Address for reprints: Professor George Matalanis, Director, Department of Cardiac Surgery, PO Box 5555, Heidelberg, Victoria, 3084, Australia (E-mail: george. matalanis@austin.org.au) 0022-5223/\$36.00

Crown Copyright $\subset 2011$ Published by Elsevier Inc. on behalf of The American Association for Thoracic Surgery

doi:10.1016/j.jtcvs.2011.01.020
}

Deep hypothermia is frequently used to compensate for the often unpredictable duration of cerebral circulatory arrest. In particular, deep hypothermia is generally the only method of spinal cord and distal organ protection used during arch repair. Deep hypothermia in itself introduces its own spectrum of morbidity, not the least of which is prolonged bypass for cooling and rewarming and coagulopathy. Perioperative hepatic and renal dysfunction, which are not infrequent in complex cases, make a further significant contribution to postoperative morbidity and mortality. ${ }^{1,5,6}$ Finally, the heart is excluded from direct perfusion for prolonged periods, mandating impeccable myocardial protection. This is sometimes difficult to achieve, particularly in the more prolonged and complex cases in which attention is diverted toward the arch repair. These are the very cases in which the myocardium is most at risk, wherein perioperative myocardial dysfunction carries a high morbidity and mortality price. ${ }^{7,8}$

We describe a technique that avoids many of these shortfalls. In particular, there are no periods of cerebral circulatory arrest and no use of deep hypothermia. Distal body circulatory arrest is often avoided or is otherwise brief. Finally, the myocardium remains perfused throughout the whole period of arch branch reconstruction, significantly reducing the duration of myocardial ischemia.

We report here our early experience with this "branchfirst continuous perfusion technique" for replacement of the aortic arch in elective and emergency settings. 


\section{Abbreviations and Acronyms \\ $\mathrm{CABG}=$ coronary artery bypass grafting \\ ICU = intensive care unit}

\section{METHODS \\ Patients and Methods}

Between 2005 and 2009, 30 patients have undergone this technique, selectively in the first year and as a routine from 2006 onward. Of these, 19 were male and 11 were female. The average age was $62 \pm 13$ years (range, 29-85 years). Preoperative demographic data are shown in Table 1. Of note, 12 were operated on as urgent/emergency cases for aortic dissection.

All patients underwent replacement of the ascending aorta and arch. Concomitant aortic root surgery was performed in 19 patients: 3 patients underwent root replacement via the David reimplantation technique, whereas other valve-sparing techniques were applied in 11 patients. Five patients underwent a Bentall procedure, with 3 and 2 patients receiving mechanical and tissue valves, respectively. Six patients underwent concomitant coronary artery bypass grafting $(\mathrm{CABG})$.

\section{Operative Technique}

Preoperative investigations include axial computed tomographic angiography of the thoracic and abdominal aorta and transesophageal echocardiography. In patients with a history of cerebrovascular disease, clinical findings of carotid bruits, significant blood pressure difference $(>20 \mathrm{~mm}$ $\mathrm{Hg}$ systolic) between left and right arms, or suspicion of atheroma of the ascending aorta or aortic arch on transesophageal echocardiogram or computed tomographic scan, further studies included carotid and transcranial Doppler, coronary angiography, and magnetic resonance angiography of the cerebral circulation. Intraoperative cerebral monitoring is performed by a combination of electroencephalogram bispectral index monitoring, cerebral oximetry (INVOS 3100; Somanetics Corp, Troy, Mich), and transcranial Doppler. The chest is opened by a median sternotomy, with a short (1-2 cm) extension along the anterior border of the left sternocleidomastoid muscle. Cardiopulmonary bypass is instituted via right atrial to both femoral artery and right axillary artery cannulation, the latter via an 8$\mathrm{mm}$ Dacron end-to-side graft, with no active cooling. Left axillary or direct ascending aortic ${ }^{9,10}$ instead of femoral artery cannulation can be used in cases of severe aortoiliac occlusive or iliofemoral dissection, or severe descending aortic atheroma.

The arch branches are exposed for a length of 3 to $4 \mathrm{~cm}$ using a "no touch" technique. To facilitate this, we divide the thymus in the midline of the anterior mediastinum and root of the neck. The innominate vein is mobilized by dividing all its tributaries. This allows complete mobility of the latter structure without having to divide it and potentially impede left cerebral venous drainage.

An appropriate-sized 3-branched Dacron graft (Vascutek Ltd, Renfrewshire, Scotland, United Kingdom) is chosen and its limbs are carefully trimmed to length, such that when it is fully pressurized, there is no risk of kinking of the branches. The innominate artery is clamped just proximal to its bifurcation and about $1 \mathrm{~cm}$ distal to its origin from the arch (Figure 1, $A)$. There is no interruption to any cerebral perfusion at this time inasmuch as there is continuing inflow to the right carotid artery via the right axillary cannula. The innominate artery is divided between the clamps and the proximal stump is oversewn, allowing removal of the proximal clamp and excellent access to the distal innominate stump, which is anastomosed to the first limb of the 3-branched graft (Figure 1,B). With the tension of the attachment of the innominate branch to the arch out of the way, there is excellent access to the left carotid artery.
TABLE 1. Preoperative clinical and operative data

\begin{tabular}{|c|c|}
\hline & Patients $(n=30$ \\
\hline \multicolumn{2}{|l|}{ Clinical } \\
\hline Age (y) & $64(54-68)$ \\
\hline \multicolumn{2}{|l|}{ Gender } \\
\hline Male & 19 \\
\hline Female & 11 \\
\hline Diabetes & 1 \\
\hline Hypertension & 19 \\
\hline Smoking & 17 \\
\hline Cerebrovascular disease & 7 \\
\hline Coronary artery disease & 9 \\
\hline \multicolumn{2}{|l|}{ Urgency } \\
\hline Elective & 18 \\
\hline Urgent/emergency & 12 \\
\hline Aortic dissection & 16 \\
\hline Acute & 12 \\
\hline Chronic & 4 \\
\hline Redo surgery & 4 \\
\hline Previous type A dissection & 3 \\
\hline Prior AVR/VSD & 1 \\
\hline \multicolumn{2}{|l|}{ Operative } \\
\hline Extracorporeal circulation time (min) & $290(227-347)$ \\
\hline Cerebral exclusion time (min) & $165(98-195)$ \\
\hline Cerebral perfusion flow rate (L/min) & $1.3(1.0-1.7)$ \\
\hline Minimum temperature $\left({ }^{\circ} \mathrm{C}\right)$ & $26(21-31)$ \\
\hline Mean perfusion pressure $(\mathrm{mm} \mathrm{Hg})$ & $71(67-77)$ \\
\hline \multicolumn{2}{|l|}{ No. of arch branches reimplanted } \\
\hline Trifurcation & 12 \\
\hline Bifurcation (innominate and left carotid) & 18 \\
\hline Aortic root replacement & 19 \\
\hline David reimplantation & 3 \\
\hline Other valve-sparing & 11 \\
\hline Bentall & 5 \\
\hline Aortic valve replacement & 2 \\
\hline Elephant trunk & 4 \\
\hline Regular & 2 \\
\hline Frozen & 2 \\
\hline
\end{tabular}

Continuous variables expressed as median (interquartile range).

A similar process is followed for the anastomosis of the second limb of the branched Dacron graft to the carotid artery (Figure 1,C). After flushing out of air and potential debris from the graft and carotid stump, clamps are removed, allowing restoration of antegrade flow (coming from the right axillary cannula) to the left carotid artery.

Once again, with the tension between the first 2 arch branches and the arch removed, there is very good exposure of the left subclavian artery. Completion of the anastomosis of the third limb of the branched graft to the left subclavian artery, if required to exclude all diseased aorta, is performed in the same manner (Figure 1,D).

In circumstances in which a large arch aneurysm interferes with access to the left subclavian artery, we use a number of maneuvers to facilitate its reconstruction. These include the following: (1) a short (1-2 cm) extension of the neck incision along the anterior border of the left sternocleidomastoid muscle can greatly improve exposure; (2) temporarily decreasing the distal perfusion pressure reduces the turgidity of the arch and avails more space; and (3) delaying the left subclavian reconstruction until the descending aorta is clamped (which does not impose a significant addition to left subclavian ischaemic time) and the arch resected leaves ample room for left subclavian anastomosis. 


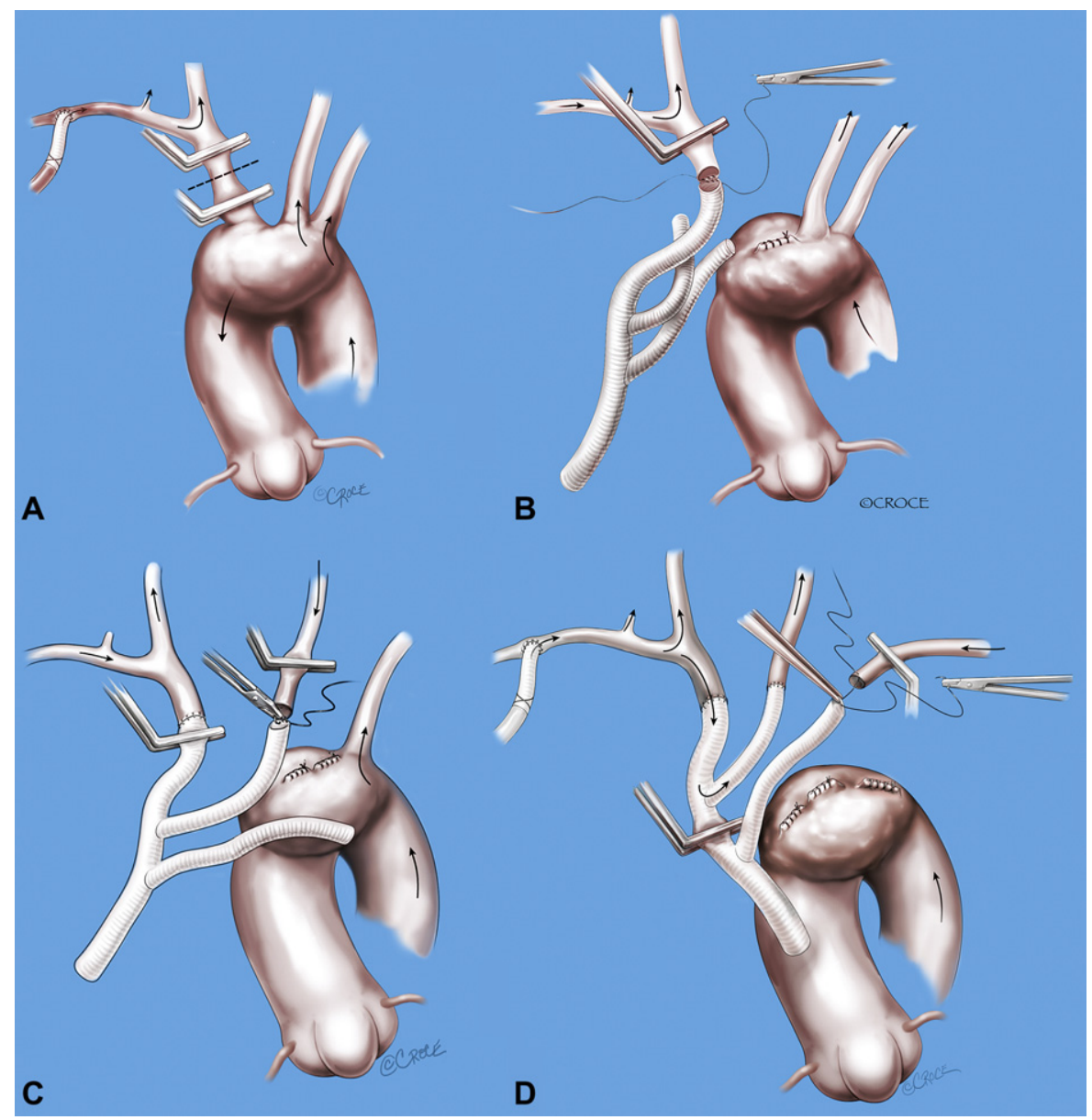

FIGURE 1. A, The innominate artery is clamped proximal to its bifurcation and distal to its origin from the arch and divided between the clamps. B, the innominate artery's proximal stump is oversewn and the distal anastomosis to the first limb of the 3-branched graft is performed. C, The second limb of the branched Dacron graft is anastomosed to the carotid artery. D, The third limb is attached to the left subclavian artery.

At this stage all 3 arch branches are perfused via the branched graft, which can be laid easily out of the field over the patient's neck. It is important to note that during this whole process the circulation was not interrupted to either the heart or the distal organs. Also of note is that all 3 arch branch anastomoses are readily in view and complete hemostasis from these sites can be ensured with ease.

The completely debranched arch is now readily mobilized. This can be assisted by temporary reduction in distal perfusion to increase the maneuverability of the arch and proximal descending aorta. Also, division of the ligamentum arteriosum is key to allowing the recurrent laryngeal nerve to "drop away" from the aortic wall. The descending aorta can be "clamped" in a number of ways (Figure 2). This depends on local conditions and whether there is a need for an elephant trunk reconstruction. It can be directly clamped at the distal end of mobilization (Figure 2, A), allowing for a simple end-to-end anastomosis at the junction of the arch and descending thoracic aorta. Alternatively, the distal descending aorta can be accessed and clamped through the posterior pericardium, behind the heart (Figure 2, B). Last, intraluminal control with a balloon catheter can also be performed (Figure 2, C). Clamping of the descending aorta ensures continuing perfusion of the abdominal organs and spinal cord, via the femoral artery cannula. In cases in which a femoral cannula could not be used, direct antegrade body perfusion can be achieved via a side port in the balloon occlusion catheter (Figure 2, C). This is the first time in the operation during which the heart is excluded from circulation, and myocardial protection is initiated and maintained at this stage by a combination of antegrade and retrograde blood cardioplegia. The remaining ascending aorta and arch is excised. An appropriate-sized tube Dacron graft with a preattached single sidearm graft (Ante-Flo Prosthesis; Vascutek Ltd) is anastomosed to the descending aorta in the desired configuration (end-to-end or elephant trunk). After completion of this anastomosis, distal body flow is changed from femoral to the sidearm graft, and a clamp is applied to the main arch graft immediately proximal to it (Figure 3,A). Once again, the potentially hazardous distal arch anastomosis is easily in view and complete hemostasis can be ensured before moving on to the next stage. The required aortic root reconstruction can now proceed as required, and anastomosis between the arch graft and root can be completed. Finally, by passing the trunk of the branched graft posterior to the innominate vein and anastomosing it to the ascending graft, in end-to-side fashion, the reconstruction is completed (Figure 3, B). Care is required in trimming the branched graft to the correct length to avoid kinking after pressurization.

\section{Data Collection and Analysis}

Operative and perfusion data are prospectively compiled in a departmental database, and further data are extracted from operation reports, perfusion reports, and intraoperative computerized records. The database was interrogated to identify all patients undergoing aortic arch replacement since the introduction of this technique in January 2005. Supplementary 


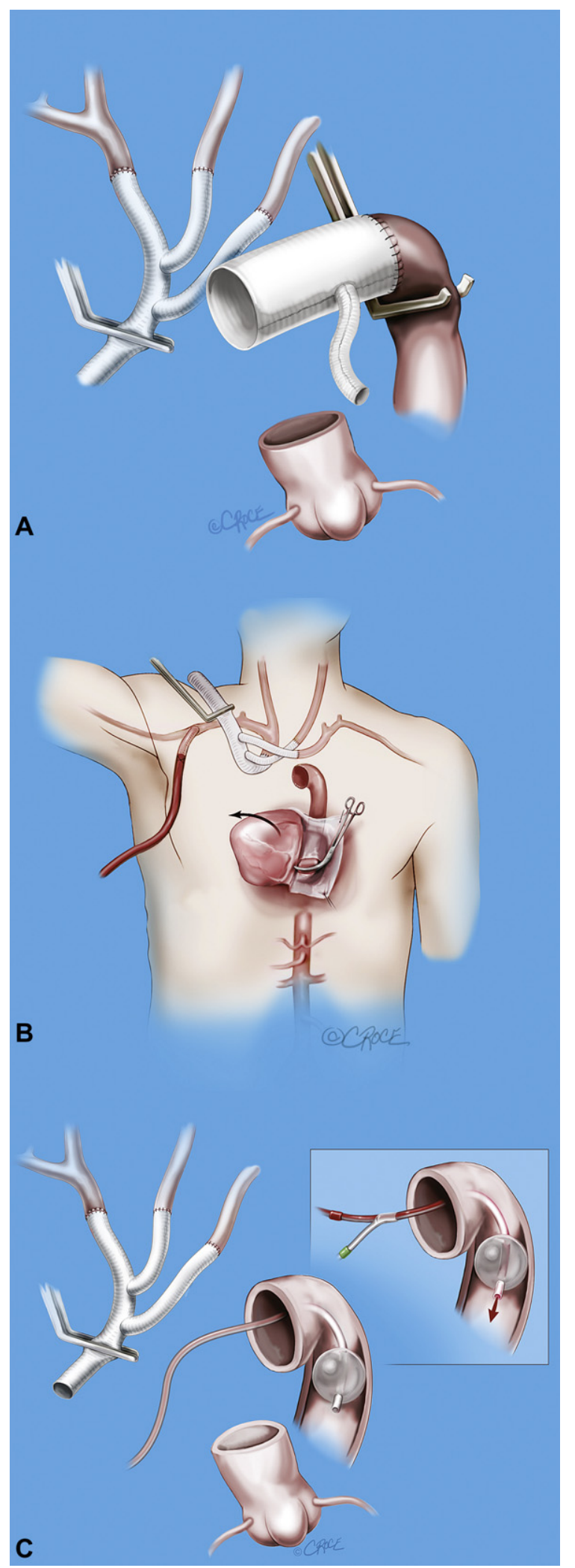

FIGURE 2. The descending aorta can be "clamped" in a number of ways: $\mathrm{A}$, at the distal end of mobilization; B, through the posterior pericardium, behind the heart; or $\mathrm{C}$, with intraluminal control with a balloon catheter.

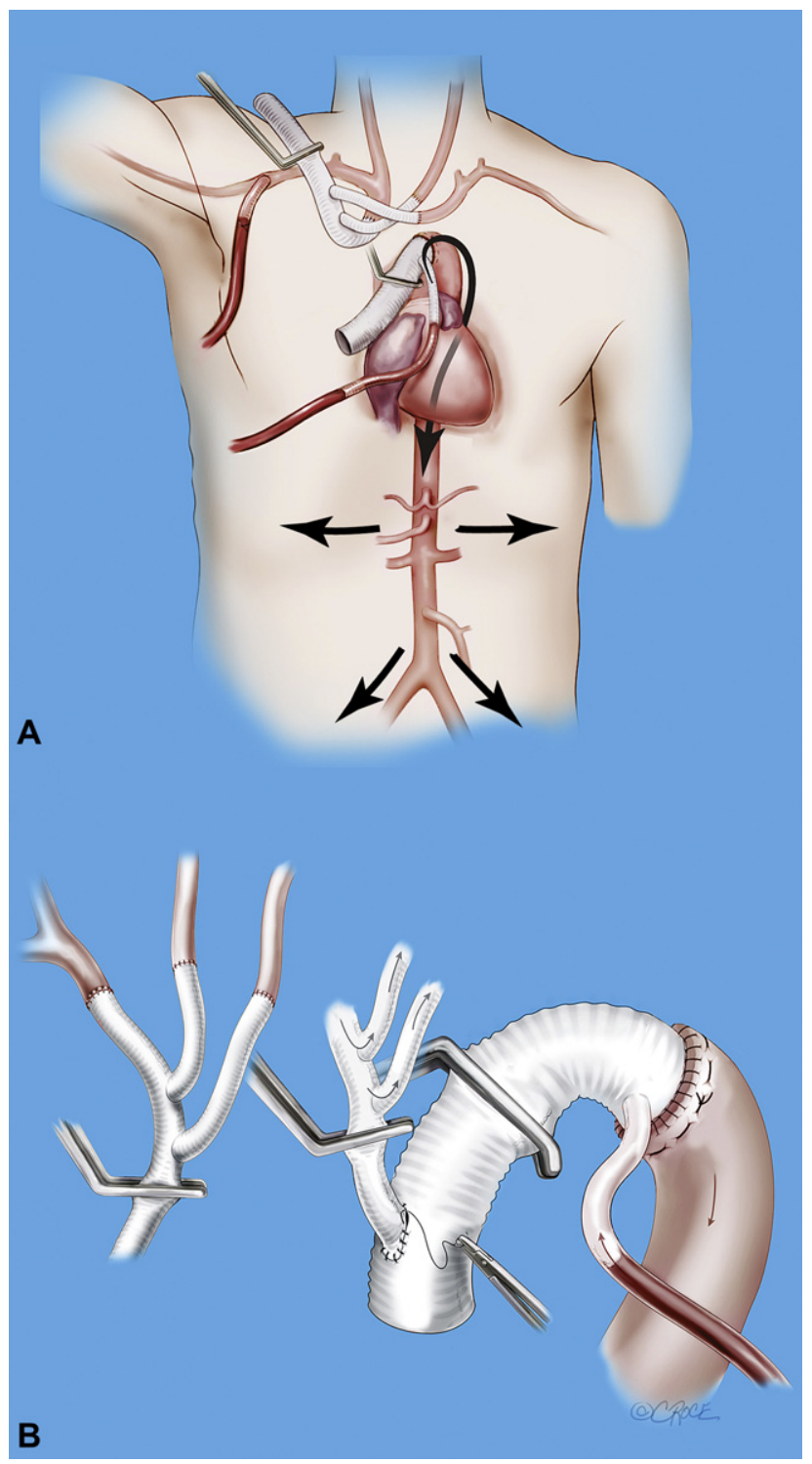

FIGURE 3. A, Distal body flow is changed from femoral to the sidearm graft. B, The trunk of the trifurcation graft is passed under the innominate vein and anastomosed to the arch graft.

demographic data were extracted from the clinical records and postoperative data from the dedicated intensive care unit (ICU) database. Data were compiled and analyzed via a Microsoft Excel spreadsheet. Documented parameters included peroperative clinical data, operative variables, and early mortality and morbidities. Continuous variables are expressed as median (first-third quartile) to account for the skewed distribution.

\section{RESULTS}

\section{Intraoperative}

Intraoperative data are displayed in Table 1. Median cardiopulmonary bypass time was 290 minutes (227-347 minutes). With greater experience and confidence, there was a trend toward higher minimum pump temperature with a median temperature of $26^{\circ} \mathrm{C}\left(21^{\circ} \mathrm{C}-31^{\circ} \mathrm{C}\right)$. Median 
cerebral perfusion flow was $1.3 \mathrm{~L} / \mathrm{min}(1.0-1.65 \mathrm{~L} / \mathrm{min})$, generating a median mean pressure of $71 \mathrm{~mm} \mathrm{Hg}(67-77$ $\mathrm{mm} \mathrm{Hg}$ ). Cerebral perfusion was maintained on a separate antegrade circuit for a median duration of 168 minutes (98-195 minutes). In some patients, especially those with chronic dissections and reoperations, distal clamping proved difficult and periods of distal circulatory arrest combined with antegrade perfusion via a balloon occlusion catheter were used with moderate hypothermia $\left(26^{\circ} \mathrm{C}-28^{\circ} \mathrm{C}\right)$.

While direct left carotid inflow is interrupted for the anastomosis of the second limb of the branched graft to the carotid, we have not seen any abnormalities in intraoperative cerebral monitoring or postoperative left cerebral hypoperfusion strokes from this maneuver.

\section{Early Postoperative Outcomes}

Postoperative outcomes are detailed in Table 2. There was 1 death owing to right ventricular failure in an 85year-old female patient. She had undergone emergency arch and root replacement in combination with CABG for a delayed presentation of an acute type A dissection with a preoperative right ventricular infarct and dysfunction. This patient received mechanical cardiac support and renal replacement therapy and died of multiorgan failure.

In $8(27 \%)$ patients, neither red blood cells nor blood products were required. Of note, $12(40 \%)$ patients were extubated within 24 hours and 14 (47\%) left the ICU within 48 hours. One patient required a tracheostomy and 4 patients returned to the operating room for bleeding.

TABLE 2. Early postoperative outcomes

\begin{tabular}{|c|c|}
\hline & Patients $(n=30)$ \\
\hline Mortality & $1 *$ \\
\hline \multicolumn{2}{|l|}{ Transfusion } \\
\hline Red cells (units) & $2(1-5)$ \\
\hline Platelets (units) & $2(1-5)$ \\
\hline Patients requiring no transfusion & 8 \\
\hline Return to operating theater for bleeding & 4 \\
\hline Mechanical cardiac support & $1^{*}$ \\
\hline Renal replacement therapy & $1 *$ \\
\hline Ischemic limb & 1 \\
\hline Ischemic gut & 0 \\
\hline Neurologic dysfunction & 2 \\
\hline Completed stroke & 0 \\
\hline Visual loss & 1 \\
\hline Hemiparesis & 1 \\
\hline Residual deficit & 0 \\
\hline Tracheostomy & 1 \\
\hline Ventilation time $(\mathrm{h})$ & $32(17-45)$ \\
\hline$\leq 24 \mathrm{~h}$ & 12 \\
\hline Total time in ICU (h) & $64(38-84)$ \\
\hline$\leq 48 \mathrm{~h}$ & 14 \\
\hline Total time in hospital (d) & $9(7-12)$ \\
\hline$\leq 7 \mathrm{~d}$ & 10 \\
\hline
\end{tabular}

Two $(6.7 \%)$ patients experienced temporary neurologic dysfunction, consisting of amaurosis fugax and left hemiparesis, from which they recovered completely (Table 2). There were no cases of global dysfunction or watershed infarcts. There was 1 case of left hand hypoperfusion after ligation of the left subclavian artery, which resolved spontaneously and did not require a carotid-subclavian bypass. Twenty-two $(73 \%)$ patients did not experience any complications.

\section{DISCUSSION}

Although major advances in the repair of diseases of the aortic arch have been made in recent years, reported outcomes are still less favorable than those for the more proximal aorta. The obvious adverse events relate to cerebral injury. The combination of profound hypothermia and antegrade cerebral perfusion forms the basis of most current techniques of organ protection during circulatory arrest for arch surgery. ${ }^{1,2}$ However, deep hypothermia carries its own spectrum of complications, ${ }^{2,3}$ not the least of which includes prolongation of bypass time and coagulopathy.

Also, antegrade perfusion techniques often include varying periods of circulatory arrest and intraluminal instrumentation of the arch branches, with attendant risks of embolization and branch injury. It is perhaps for these reasons that many series show that cerebral morbidity has not been dramatically reduced compared with deep hypothermia alone, ${ }^{11,12}$ with embolic stroke undoing the advantage of cerebral perfusion.

The approach used in our technique evolved from the appreciation of the richness of the collateral network between the right and left halves of the head and neck, especially through midline structures such as the tongue and thyroid gland as well as the upper and lower body, over and above the circle of Willis. The situation of individual proximal arch branch clamping is entirely different from that of carotid endarterectomy performed without shunting, where the sole collaterals to the ipsilateral hemisphere are via the circle of Willis. Even there, when clamp times are kept below 15 minutes, the hypoperfusion stroke risk is small. ${ }^{13-15}$ Furthermore, in the case of aortic arch replacement, there are many added buffers against hypoperfusion: these include the brief duration of interrupted flow (typically around 10 minutes, inasmuch as there is usually no need for endarterectomy and only a simple end-to-end anastomosis is required), heparinization, control of overall perfusion by the bypass circuit, and a mild degree of hypothermia.

Perhaps less appreciated are the consequences of sublethal myocardial and visceral organ injury from prolonged periods of suboptimal flow, which can manifest their effects through coagulopathy, sepsis, gastrointestinal bleeding, and multiorgan failure. Complex arch repairs using standard techniques of deep hypothermia and antegrade perfusion often ignore the effects of prolonged cardiac exclusion and 
distal body circulatory arrest. In our technique, cardiac perfusion is maintained throughout the whole of the arch branch reconstruction phase, significantly reducing the period of time of reliance on cardioplegia. Maintenance of distal organ and especially liver and kidney perfusion reduces the risk of postoperative renal dysfunction and coagulopathy. We believe this is reflected by the relatively short median ventilation and ICU stay times, low need for renal replacement therapy, and good hemostasis.

The relatively low transfusion rate resulted from the preservation of clotting by reduction in coagulopathy, minimal cooling, and the technique whereby hemostasis from each anastomosis is ensured after it is pressurized before continuing to the next step. In fact, after the reconstruction is completed, all suture lines are easily visible and accessible should further hemostasis be required.

The single death occurred in the oldest patient, who had several risk factors, namely, age greater than 70 years, female gender, presence of preoperative right ventricular failure, and requirement for CABG. Reported rates of permanent stroke in contemporary aortic surgery range from $4.0 \%$ to $6.1 \% .^{1,3,4,7,11}$ The 2 transient neurologic deficits sustained in our series give an estimated incidence in line with these other published series.

Although not completely comparable and not contemporaneous, previous experience in our unit using deep hypothermic circulatory arrest and traditional arch replacement techniques was associated with ostensibly poorer outcomes. ${ }^{16}$ The mortality and stroke rates were higher and the length of intubation, ICU stay, and hospital stay were also longer. Our early experience with this technique is encouraging, with low mortality $(3 \%)$ and a low incidence of renal, gastrointestinal, hepatic, and ventilatory failure.

Additional positive secondary outcomes we have noticed include the ease of achievement of complete hemostasis, with a quarter of patients not requiring blood products, and the rapidity of awakening and clarity of conscious state, which was akin to patients undergoing routine cardiac procedures. Importantly, complete and uncompromising repairs even in the most complex arch disease were performed in an unhurried and more relaxed fashion.

There may be a number of potential disadvantages of this technique. The issue of left carotid or left vertebral ischemia during individual branch clamping has already been discussed. In fact, experience with stent-grafting techniques for arch repair involving off-pump interposition grafts from the ascending aorta to the brachiocephalic ${ }^{17,18}$ vessels has shown promising results.

There may be concern that clamping of the arch branches in the presence of arch and arch branch atheroma may result in thromboembolism. Although this is a valid objection, there are a number of key maneuvers to avoid this. Branch mobilization is performed by the "no touch" method, dissecting tissue away from the vessel, rather than handling the vessel itself. The arch branch is clamped distally initially in the area more remote from the arch, and thus less likely to contain atheroma, before the proximal clamp. The proximal clamp itself is applied 1 to $2 \mathrm{~cm}$ beyond the origin of the branch to avoid retrograde embolization of the arch. In cases in which preoperative or intraoperative data suggest significant arch atheroma, the branches can be mobilized and clamped more distally in the neck, or alternative standard techniques can be used.

The use of femoral cannulation may draw objections on grounds such as retrograde embolization and malperfusion. However, femoral access has been shown to be safe even in cases of acute aortic dissection. ${ }^{19}$ Left axillary or direct ascending aortic cannulation, ${ }^{9,10}$ instead of femoral artery cannulation, can be used in cases of severe aortoiliac occlusive or iliofemoral dissection or severe descending aortic atheroma. Direct ascending cannulation can be safely performed with the assistance of epiaortic ultrasound. ${ }^{20}$ The dual inflow source is important not only to provide distal body perfusion during arch branch reconstruction, but also to lower perfusion pressure gradients, avoiding problems such as hyperperfusion of the right hemisphere and blood cell trauma, were right axillary cannulation to be used alone.

There may also be concern about the applicability of this technique in the more complex cases, such as reoperations, graft or valve infections, or severe aortic regurgitation. In fact, these cases may well be more suited for this technique. The cerebral branches can in fact be mobilized and reconstructed before even entering the pericardium, ensuring cerebral flow in case of a disaster on re-entry. ${ }^{21}$

We acknowledge limitations of this series, primarily its small size, institutional basis, and evolution of technique from initial to most recent experience. Inevitably, increasing experience is shortening bypass and ischemic times and improving clinical outcomes after "branch-first continuous perfusion" aortic arch replacement in our experience.

\section{CONCLUSIONS}

This technique brings us closer to the goal of arch surgery without cerebral and, in many cases, visceral circulatory arrest and the morbidity of deep hypothermia. Early results are encouraging. Analysis of outcomes in future patients beyond this learning curve phase and in other institutions will reveal the full potential of this approach.

We acknowledge Dr John McKay in addition to Mss Margaret Shaw and Beverley Toone. We also thank Ms Beth Croce for her excellent illustrations.

\section{References}

1. Kazui T, Yamashita K, Washiyama N, Terada H, Bashar AHM, Suzuki K, et al. Aortic arch replacement using selective cerebral perfusion. Ann Thorac Surg. 2007;83:S796-8. 
2. Harrington DK, Fragomeni F, Bonser RS. Cerebral perfusion. Ann Thorac Surg. 2007;83:S799-804.

3. Reich DL, Uysal S, Sliwinski M, Ergin MA, Kahm R, Konstadt S, et al. Neuropsychologic outcome after deep hypothermic circulatory arrest in adults. J Thorac Cardiovasc Surg. 1999;117:156-63.

4. Küçüker SA, Özatik MA, SarItas A, Tasdemir O. Arch repair with unilateral antegrade cerebral perfusion. Eur J Cardiothorac Surg. 2005;27:638-43.

5. Arnaoutakis GJ, Bihorac A, Martin TD, Hess PJ Jr, Klodell CT, Ejaz AA, et al. RIFLE criteria for acute kidney injury in aortic arch surgery. J Thorac Cardiovasc Surg. 2007;134:1554-61.

6. Ueno T, Itoh T, Rikitake K, Ohtubo S, Hamada M, Okazaki Y. Correlation between age and vital organ function following deep hypothermic circulatory arrest. J Cardiovasc Surg (Torino). 2002;43:167-73.

7. Svensson LG, Nadolny EM, Kimmel WA. Multimodal protocol influence on stroke and neurocognitive deficit prevention after ascending/arch aortic operations. Ann Thorac Surg. 2002;74:2040-6.

8. Yağdi T, Atay Y, Cikirikçioğlu M, Boğa M, Posacioğlu H, Ozbaran M, et al. Determinants of early mortality and neurological morbidity in aortic operations performed under circulatory arrest. J Card Surg. 2000;15:186-93.

9. Neri E, Massetti M, Capannini G, Carone E, Tucci E, Diciolla F, et al. Axillary artery cannulation in type A aortic dissection operations. J Thorac Cardiovasc Surg. 1999;118:324-9.

10. Kamiya H, Kallenbach K, Halmer D, Ozsöz M, Ilg K, Lichtenberg A, et al. Comparison of ascending aorta versus femoral artery cannulation for acute aortic dissection type A. Circulation. 2009;120:S282-6.

11. Gega A, Rizzo JA, Johnson MH, Tranquilli M, Farkas EA, Elefteriades JA. Straight deep hypothermic arrest: experience in 394 patients supports its effectiveness as a sole means of brain preservation. Ann Thorac Surg. 2007;84:759-67.
12. Percy A, Widman S, Rizzo JA, Tranquilli M, Elefteriades JA. Deep hypothermic circulatory arrest in patients with high cognitive needs: full preservation of cognitive abilities. Ann Thorac Surg. 2009;87:117-23.

13. Bland JE, Lazar ML. Carotid endarterectomy without shunt. Neurosurgery. 1981; 8:153-7.

14. Carmichael JD. Carotid surgery in the community hospital: 467 consecutive operations. Arch Surg. 1980;115:937-9.

15. Collice M, Arena O, Fontana RA, Mola M, Galbiati N. Role of EEG monitoring and cross-clamping duration in carotid endarterectomy. J Neurosurg. 1986;65 815-9.

16. Matalanis G, Hata M, Buxton BF. A retrospective comparative study of deep hypothermic circulatory arrest, retrograde, and antegrade cerebral perfusion in aortic arch surgery. Ann Thorac Cardiovasc Surg. 2003;9:174-9.

17. Wilson YS, Joseph EB, Frank WB, Edward YW, Ronald MF, Alberto P. The hybrid total arch repair: brachiocephalic bypass and concomitant endovascular aortic arch stent graft placement. J Card Surg. 2007;22:97-102.

18. Bavaria JE, Appoo JJ, Makaroun MS, Verter J, Yu Z-F, Mitchell RS. Endovascular stent grafting versus open surgical repair of descending thoracic aortic aneurysms in low-risk patients: a multicenter comparative trial. $J$ Thorac Cardiovasc Surg. 2007;133:369-77.e4.

19. Fusco DS, Shaw RK, Tranquilli M, Kopf GS, Elefteriades JA. Femoral cannulation is safe for Type A dissection repair. Ann Thorac Surg. 2004;78:1285-9.

20. Dávila-Román VG, Phillips KJ, Daily BB, Dávila RM, Kouchoukos NT, Barzilai B. Intraoperative transesophageal echocardiography and epiaortic ultrasound for assessment of atherosclerosis of the thoracic aorta. J Am Coll Cardiol. 1996;28:942-7.

21. Bachet J, Pirotte M, Laborde F, Guilmet D. Reoperation for giant false aneurysm of the thoracic aorta: how to reenter the chest? Ann Thorac Surg. 2007;83:1610-4. 